\title{
Publisher Correction: Widespread patterns of gene loss in the evolution of the animal kingdom
}

Cristina Guijarro-Clarke, Peter W. H. Holland (D) and Jordi Paps (D)

Correction to: Nature Ecology \& Evolution https://doi.org/10.1038/s41559-020-1129-2, published online 24 February 2020.

In the version of this Brief Communication originally published, the name of the first author was incorrectly inserted into the first sentence of the abstract. The sentence should have read as follows: "The animal kingdom shows an astonishing diversity, the product of over 550 million years of animal evolution". This has now been corrected.

Published online: 27 February 2020

https://doi.org/10.1038/s41559-020-1159-9

() The Author(s), under exclusive licence to Springer Nature Limited 2020 